\title{
Modulation of Thalamic Nociceptive Processing after Spinal Cord Injury through Remote Activation of Thalamic Microglia by Cysteine-Cysteine Chemokine Ligand 21
}

\author{
Peng Zhao, ${ }^{1,2}$ Stephen G. Waxman, ${ }^{1,2}$ and Bryan C. Hains ${ }^{1,2}$ \\ ${ }^{1}$ Department of Neurology and Center for Neuroscience and Regeneration Research, Yale University School of Medicine, New Haven, Connecticut 06510, \\ and ${ }^{2}$ Rehabilitation Research Center, Veterans Affairs Connecticut Healthcare System, West Haven, Connecticut 06516
}

\begin{abstract}
Spinal cord injury (SCI) results in the generation and amplification of pain caused in part by injury-induced changes in neuronal excitability at multiple levels along the sensory neuraxis. We have previously shown that activated microglia, through an ERK (extracellular signal-regulated kinase)-regulated $\mathrm{PGE}_{2}$ (prostaglandin $\mathrm{E}_{2}$ ) signaling mechanism, maintain neuronal hyperexcitability in the lumbar dorsal horn. Here, we examined whether microglial cells in the thalamus contribute to the modulation of chronic pain after SCI, and whether microglial activation is governed by spinally mediated increases in the microglial activator cysteine-cysteine chemokine ligand 21 (CCL21). We report that CCL21 is upregulated in dorsal horn neurons, that tissue levels are increased in the dorsal horn and ventral posterolateral (VPL) nucleus of the thalamus 4 weeks after SCI, and that the increase can be differentially reduced by spinal blockade at T1 or L1. In intact animals, electrical stimulation of the spinothalamic tract induces increases in thalamic CCL21 levels. Recombinant CCL21 injected into the VPL of intact animals transiently activates microglia and induces pain-related behaviors, effects that could be blocked with minocycline. After SCI, intra-VPL antibody-mediated neutralization of CCL21 decreases microglial activation and evoked hyperexcitability of VPL neurons, and restores nociceptive thresholds to near-normal levels. These data identify a novel pathway by which SCI triggers upregulation of the neuroimmune modulator CCL21 in the thalamus, which induces microglial activation in association with pain phenomena.
\end{abstract}

Key words: thalamus; microglia; CCL21; pain; spinal cord injury; hypersensitivity

\section{Introduction}

Neuroimmune alterations contribute to maladaptive changes in nociceptive processing after nervous system injury. Microglia have been implicated in the initiation phase of peripheral injuryinduced pain (Coyle, 1998; Fu et al., 1999; Watkins et al., 2001, 2007; Jin et al., 2003; Ledeboer et al., 2005; DeLeo et al., 2006) and become activated via local release of factors such as interleukin-1 $\beta$ (IL-1 $\beta$ ), IL-6, tumor necrosis factor $\alpha$ (TNF $\alpha$ ), ATP, substance P, and fractalkine (Ji and Strichartz, 2004; Marchand et al., 2005; Tsuda et al., 2005; Wieseler-Frank et al., 2005; Moalem and Tracey, 2006).

Microglia also become activated in the spinal cord after clinical (Chang, 2007) and experimental spinal cord injury (SCI) (Popovich et al., 1997; Hains et al., 2003; Sroga et al., 2003; Nesic et al., 2005; Zai and Wrathall, 2005; Crown et al., 2006; Hains and

\footnotetext{
Received April 2, 2007; revised June 20, 2007; accepted June 26, 2007.

This work was supported in part by grants from the Medical Research Service and Rehabilitation Research Service, Department of Veterans Affairs, and the National Multiple Sclerosis Society. B.C.H. was funded by Pfizer (Scholar's Grant in Pain Medicine), The Dana Foundation, and The American Pain Society. The Center for Neuroscience and Regeneration Research is a Collaboration of the Paralyzed Veterans of America and the United Spinal Association.

Correspondence should be addressed to Dr. Bryan C. Hains, Center for Neuroscience and Regeneration Research, Department of Neurology, Yale University School of Medicine, 950 Campbell Avenue, Building 34, West Haven, CT 06516. E-mail: bryan.hains@yale.edu.

D0I:10.1523/JNEUROSCI.2209-07.2007

Copyright $\odot 2007$ Society for Neuroscience $\quad$ 0270-6474/07/278893-10\$15.00/0
}

Waxman, 2006; Zhao et al., 2007). The identification of unique, injury-induced regional stimulators of microglia will be critical to our understanding, as well as management, of signaling pathways underlying chronic pain after SCI. Microglia in the lumbar dorsal horn become activated and help to maintain hyperexcitability of nociceptive neurons associated with pain-related behaviors (Hains and Waxman, 2006) through an extracellular signalregulated kinase (ERK)-regulated microglia-neuron prostaglandin $\mathrm{E}_{2}\left(\mathrm{PGE}_{2}\right)$ signaling mechanism (Zhao et al., 2007).

Dorsal horn nociceptive neurons project rostrally to thirdorder neurons in the ventral posterolateral (VPL) nucleus of the thalamus, which is involved in sensory-discriminative aspects of pain processing (Jones 1998). VPL neurons become hyperexcitable after SCI (Hains et al., 2005, 2006). In this new configuration, spinal and thalamic somatosensory circuitry amplify and generate abnormal nociceptive impulses, which are likely interpreted by the brain as inappropriate or excessive pain (Yezierski 2001; Waxman and Hains, 2006). Thalamic changes have been associated with pain after SCI in humans (Lenz et al., 1989; Pattany et al., 2002), primates (Weng et al., 2000), and rats (Gerke et al., 2003; Koyama et al., 1993; Hubscher and Johnson, 2006), but the molecular determinants of these changes are unclear.

We considered the possibility that microglia contribute to alterations in nociceptive processing within the VPL after SCI. Rapid morphological transformation and homing of microglia to 
sites of injury may can be induced by the local chemokines such as cysteine-cysteine chemokine ligand 21 (CCL21; Exodus-2; 6Ckine) (Columba-Cabezas et al., 2003; Carbonell et al., 2005; de Jong et al., 2005; Kurpius et al., 2006), the receptor for which (CXCR3, CCR7) is expressed by microglia (Rappert et al., 2002; Dijkstra et al., 2006). Indeed, CCL21 upregulation and vesicular packaging are observed in an in vitro model of neuronal injury (de Jong et al., 2005).

In this report, we demonstrate that microglia become activated in the VPL after SCI, that remote transsynaptic microglial activation contributes to neuronal hyperexcitability and pain behaviors after SCI, and that CCL21 plays an important role in this process.

\section{Materials and Methods}

Animal care. Experiments were performed in accordance with National Institutes of Health guidelines for the care and use of laboratory animals; all animal protocols were approved by the Yale University Institutional Animal Care and Use Committee. Adult male Sprague Dawley rats (200$275 \mathrm{~g}$ ) were used for this study. Animals were housed under a $12 \mathrm{~h}$ light/dark cycle in a pathogen-free area with ad libitum access to water and food.

Spinal cord stimulation. Unilateral electrical stimulation of the spinothalamic tract (STT) was performed at spinal segment L1 in intact rats. Under pentobarbital anesthesia (40 mg/kg, i.p.), a partial laminectomy was performed, and a platinum stimulating electrode was stereotaxically inserted into the ventrolateral funiculus corresponding to the location of the STT. Stimulation was performed ( $30 \mathrm{~V} ; 0.5 \mathrm{~ms}$ pulse duration) at 10 $\mathrm{Hz}$ for 8 min (Martin et al., 1990; Yen et al., 1991), which is consistent with firing rates observed after SCI during painful stimulation (Hains et al., 2003). Animals were decapitated 20-25 min after stimulation, and thalamic tissue was collected for histological or enzyme immunoassay.

Spinal cord injury. Rats were deeply anesthetized with ketamine/xylazine $(80 / 5 \mathrm{mg} / \mathrm{kg}$, i.p.). Spinal contusion injury (SCI) was produced at spinal segment T9 using the MASCIS/NYU impact injury device (Gruner, 1992). A $10 \mathrm{~g}, 2.0 \mathrm{~mm}$ diameter rod was released from a $25 \mathrm{~mm}$ height onto the exposed spinal cord. For sham surgery, animals underwent laminectomy and placement into the vertebral clips of the impactor without impact injury. After SCI or sham surgery, the overlying muscles and skin were closed in layers with 4-0 silk sutures and staples, respectively, and the animal was allowed to recover on a $30^{\circ} \mathrm{C}$ heating pad. Postoperative treatments included saline $(2.0 \mathrm{cc}$, s.c.) for rehydration, and Baytril ( $0.3 \mathrm{cc}, 22.7 \mathrm{mg} / \mathrm{ml}$, s.c.; twice daily) to prevent urinary tract infection. Bladders were manually expressed twice daily until reflex bladder emptying returned, typically by $10 \mathrm{~d}$ after injury. After surgery, animals were maintained under the same preoperative conditions, and fed ad libitum.

Blockade of spinal afferent barrage to the thalamus. Four weeks after SCI, under pentobarbital anesthesia $(40 \mathrm{mg} / \mathrm{kg}$, i.p.), the spinal cord was exposed by laminectomy either rostral to the SCI site at spinal segment $\mathrm{T} 1$, or caudal to the site of injury (but rostral to the lumbar enlargement) at spinal segment L1. A solution of $2 \%$ lidocaine was topically applied to the dorsal and lateral surfaces of the spinal cord followed by complete cord transection with iridectomy scissors as established previously by us (Hains et al., 2005). Tissue was collected 10-16 min after cord transection for histological or enzyme immunoassay (EIA) analysis.

Intra-VPL drug delivery. Under ketamine/xylazine $(80 / 5 \mathrm{mg} / \mathrm{kg}$, i.p.) or halothane (3\% induction, $1.5 \%$ maintenance by facial mask, for $\alpha$ CCL21 injections) anesthesia, rats were placed into a stereotaxic frame and bilaterally injected according to coordinates corresponding to the VPL nucleus (bregma, $-3.14 \mathrm{~mm}$; lateral, $2.6 \mathrm{~mm}$; vertical, $4.8 \mathrm{~mm}$ ). Injections were performed at 4 weeks after injury for SCI rats, and at age-matched time points for non-SCI animals. In a $1.0 \mu \mathrm{l}$ total volume slowly over a period of $6 \mathrm{~min}$, animals received artificial CSF (aCSF) (1.3 $\mathrm{mm} \mathrm{CaCl} \cdot 2 \mathrm{H}_{2} \mathrm{O}, 2.6 \mathrm{~mm} \mathrm{KCl}, 0.9 \mathrm{~mm} \mathrm{MgCl}, 21.0 \mathrm{~mm} \mathrm{NaHCO}, 2.5 \mathrm{~mm}$ $\mathrm{Na}_{2} \mathrm{HPO}_{4} \cdot 7 \mathrm{H}_{2} \mathrm{O}, 125.0 \mathrm{~mm} \mathrm{NaCl}$, prepared in sterile $\mathrm{H}_{2} \mathrm{O}$ ) (Hains and Waxman, 2006), recombinant mouse CCL21 (rmCCL21) (1.2 ng; R\&D
Systems, Minneapolis, MN) (Elzaouk et al., 2006), goat anti-mouse CCL21 neutralizing antibody ( $\alpha$ CCL21) (5 ng; R\&D Systems) (Liu et al., 2005), affinity-purified normal goat IgG (13 ng; R\&D Systems) (Milligan et al., 2005), and/or minocycline (10 $\mu \mathrm{g}$; Sigma, St. Louis, MO) (Ledeboer et al., 2005; Hains and Waxman, 2006), which potently downregulates the activity of microglia in vivo (Raghavendra et al., 2003; Hua et al., 2005; Ledeboer et al., 2005). A separate group of intact rats underwent identical intra-VPL injections of minocycline or $\alpha$ CCL21 to test for injection-induced effects on microglial activation and nociceptive thresholds. Drug doses were predetermined and verified by our group. Injection locations were assessed histologically.

Immunostaining and quantification. Immunostaining was performed at 4 weeks after injury for SCI rats, and at age-matched time points for control animals ( $n=4-7$ sections/ $4-8$ animals/group). Rats were deeply anesthetized with ketamine/xylazine $(80 \mathrm{mg} / 5 \mathrm{~kg}$, i.p.) and perfused intracardially with $0.01 \mathrm{~m}$ PBS followed by $4 \%$ cold, buffered paraformaldehyde. Tissue was postfixed for $15 \mathrm{~min}$ in $4 \%$ paraformaldehyde PBS and cryopreserved overnight at $4^{\circ} \mathrm{C}$ in $30 \%$ sucrose PBS. Coronal cyosections $(12 \mu \mathrm{m})$ corresponding to the lumbar enlargement (L4) or VPL were incubated at room temperature in the following: (1) blocking solution (PBS containing 5\% NGS, $2 \%$ BSA, $0.1 \%$ Triton X-100, and $0.02 \%$ sodium azide) for $30 \mathrm{~min}$; (2) primary antibody: mouse anti-Cd11b/c clone OX-42 raised against complement receptor 3 (1:250; BD Biosciences, San Jose, CA) (Hains and Waxman, 2006; Zhao et al., 2007), rabbit anti-CCL21 (1:250; Abcam, Cambridge, MA), mouse antineuron-specific nuclear protein NeuN (1:500; Millipore, Temecula, CA), or mouse anti-glutamate (1:1000; Millipore) overnight in blocking solution at $4^{\circ} \mathrm{C}$; (3) PBS, six times for 5 min each; and (4) appropriate secondary antibodies in blocking solution for $2 \mathrm{~h}$; (5) PBS, six times for 5 min each. Control experiments were performed without primary or secondary antibodies, preabsorption treatments (rmCCL21; $50 \mathrm{ng} / \mathrm{ml}$; R\&D Systems; in the case of anti-CCL21), and blocking substances (peptides) obtained from manufacturers.

Quantification of cellular signal intensity of digitally captured images was performed by a blinded observer using IPLab Spectrum, version 3.0, software (Scanalytics, Fairfax, VA). Percentage of field analysis was performed using MetaMorph (Molecular Devices, Sunnyvale, CA) to provide a quantitative estimate (proportional area) of changes in the activation state of microglial cells (Popovich et al., 1997; Hains and Waxman, 2006; Zhao et al., 2007) in the VPL, ventral posteromedial (VPM), and reticular (Rt) thalamic nuclei $\left(\sim 0.50 \mathrm{~mm}^{2}\right)$ based on atlas boundaries, after subtraction of background signal. Resting glia were classified as having small compact somata bearing long thin ramified processes. Activated glia exhibited marked cellular hypertrophy, and retraction of processes such that the process length was less than the somal diameter. Background levels of signal were subtracted, and control and experimental conditions were evaluated in identical manners.

Enzyme immunoassays. From sham-operated and animals 4 weeks after SCI and/or treatment, after microdissection of spinal cord segments T9 and L4, and ventrobasal thalamus, tissue levels of CCL21 (Quantikine Assay; R\&D Systems) or proinflammatory cytokines and microglial activators IL-1 $\beta$, IL-6, TNF $\alpha$, fractalkine, monocyte chemoattractant protein 1 (MCP-1) (CCL2), macrophage-inflammatory protein $1 \alpha$ (MIP$1 \alpha$ ), and regulated on activation normal T cell expressed and secreted (RANTES) (CCL5) (Pierce SearchLight Multiplex Assay; Pierce Biotechnology, Woburn, MA) were assayed in triplicate using quantitative enzyme immunoassay, from the following groups: intact and sham operated (age-matched), SCI (all 4 weeks post-SCI), SCI plus rostral block, SCI plus caudal block, side ipsilateral to STT stimulation, side contralateral to STT stimulation. After decapitation, thalamic tissue was rapidly microdissected, rinsed free of blood with PBS, weighed, and flash-frozen. Tissue was not pooled. Tissue was homogenized in ice-cold lysis buffer (0.1 M phosphate, $\mathrm{pH} 7.4,1 \mathrm{~mm}$ EDTA) containing a complete protease inhibitor mixture (Roche, Mannheim, Germany) using a tube pestle, followed by centrifugation at $1500 \times g$ for $10 \mathrm{~min}$. According to the manufacturer, the CCL21 assay demonstrates little cross-reactivity between structurally related MCP-1, MCP-5, MIP- $1 \alpha$, or RANTES that may also effect microglial activation. Absorbance values of standards and samples were corrected by subtraction of the background value to ac- 

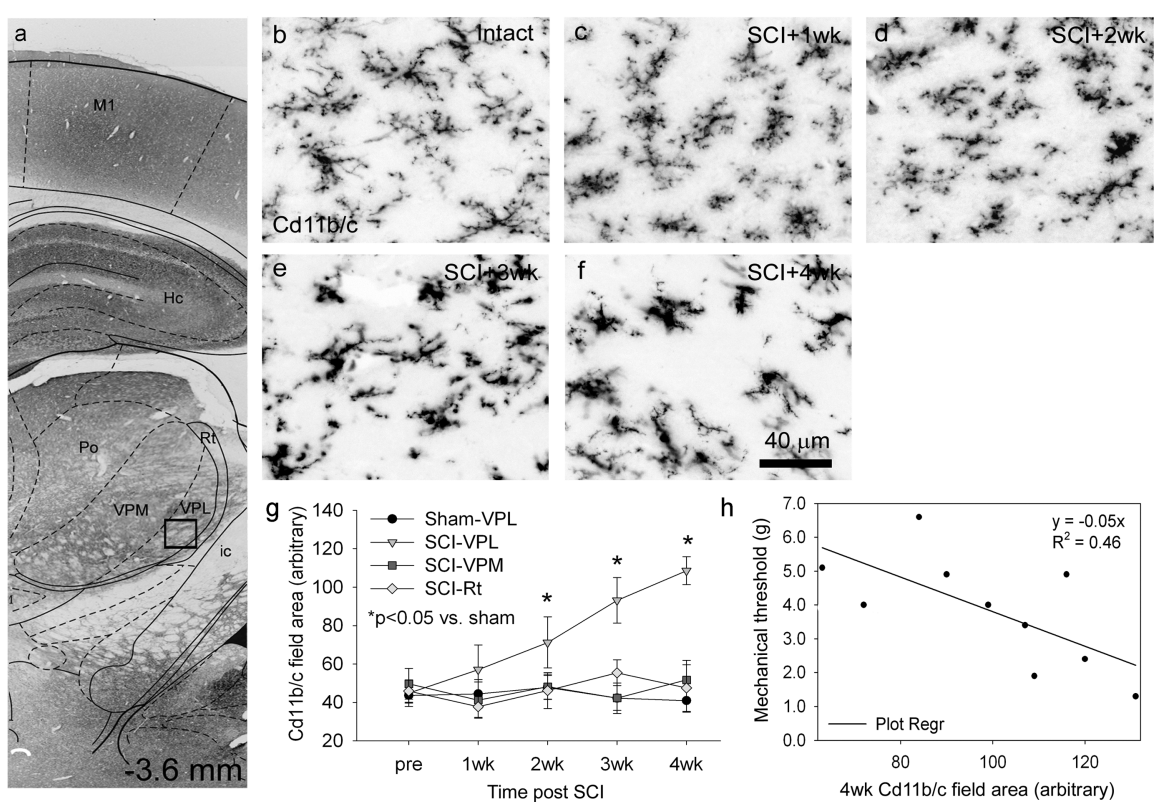

Figure 1. Progressive microglial activation in the VPL after SCl and pain behaviors. $\boldsymbol{b}, \mathrm{C} 11 \mathrm{~b} / \mathrm{c}(0 \mathrm{X}-42)$ immunostaining revealed the presence of microglia in the VPL that exhibit the resting morphotype. Approximate positions of relevant anatomical structures are shown in an atlas overlay (Paxinos and Watson, 1998): M1, motor cortex; Hc, hippocampus; Po, posterior thalamic nucleus; ic, internal capsule. $\boldsymbol{c}-\boldsymbol{f}$, One to 4 weeks after T9 $\mathrm{SCl}$, microglia progressively demonstrated the activated morphotype. $\boldsymbol{g}$, Quantification of percentage field area for $\mathrm{Cd} 11 \mathrm{~b} / \mathrm{c}$ revealed significant $\left({ }^{*} p<0.05\right)$ microglial activation starting at 2 weeks after injury. Error bars indicate SD. $\boldsymbol{h}$, Correlation analysis at 4 weeks after $\mathrm{SCl}$ showed a strong relationship between $\mathrm{Cd} 11 \mathrm{~b} / \mathrm{c}$ field area and mechanical nociceptive thresholds for individual animals. Plot regression line and key values are shown.

count for absorbance attributable to nonspecific binding and comparing to standard curves of known protein concentrations.

Thalamic unit recordings. Under constant pentobarbital $(40 \mathrm{mg} / \mathrm{kg}$, i.p.) anesthesia, activity from multireceptive units with hindpaw receptive fields responding to both innocuous and noxious inputs were recorded from the VPL (bregma, -3.14; lateral, 2.6; vertical, 4.8) from intact, SCI plus IgG, and SCI plus $\alpha$ CCL21 animals by established methods (Hains et al., 2005, 2006). Recordings were obtained 4 weeks after injury and drug delivery for SCI rats.

Rectal temperature was maintained at $37^{\circ} \mathrm{C}$. The head was fixed in a stereotaxic apparatus (Kopf Instruments, Tujunga, CA) and skin incision and a limited craniotomy exposed the brain surface vertical to the recording sites within the thalamus. Neuronal units were isolated from the VPL (bregma, $-3.14 \mathrm{~mm}$; lateral, $2.6 \mathrm{~mm}$; vertical, $4.8 \mathrm{~mm}$ ). Extracellular single-unit recordings were made with a low-impedance $5 \mathrm{M} \Omega$ tungsten insulated microelectrode (A-M Systems, Carlsborg, WA). Electrical signals were amplified and filtered at $300-3000 \mathrm{~Hz}$ (DAM80; World Precision Instruments, Sarasota, FL), processed by a data collection system (CED 1401+; Cambridge Instruments, Cambridge, UK), and stored on a computer (Pentium 4 PC; Dell, Austin, TX) to construct peristimulus time histograms or wavemarks. The stored digital record of individual unit activity was analyzed off-line with Spike2 software (version 5.09; Cambridge Electronic Design, Cambridge, UK).

Units were only sampled if they possessed hindpaw receptive fields. Once a cell was identified, its receptive field was mapped and stimulated. Background activity was measured followed by cutaneous receptive field mapping with von Frey filaments and/or brief pinches. Three mechanical stimuli were routinely applied: (1) phasic brush, (2) pressure (144 $\mathrm{g} / \mathrm{mm}^{2}$ force arterial clip), and (3) pinch ( $583 \mathrm{~g} / \mathrm{mm}^{2}$ force arterial clip). Multireceptive units were identified by their responsiveness to brush, press, and pinch. Background activity was recorded for $10 \mathrm{~s}$ and stimuli applied serially for $10 \mathrm{~s}$, separated by $10 \mathrm{~s}$ of baseline activity. Care was taken to ensure that the responses were maximal, that each stimulus was applied to the primary receptive field of the unit, and that isolated units remained intact and held for the duration of each experiment using template matching routines. Neurons responding mainly to joint move- ment or to probing subcutaneous tissue were excluded from analysis. Evoked responses were calculated by subtracting the prestimulus baseline activity to yield net number of spikes per response. Units were considered to be hyperresponsive if evoked discharge rates were $>150 \%$ of control levels. At the conclusion of each experiment, direct current ( $1 \mathrm{~mA}$ for $20 \mathrm{~s})$ was passed through the recording electrode to mark the recording site.

Somatosensory behavioral testing. Baseline thresholds were established before sham surgery or 4 weeks after SCI, and then performed after surgery and/or drug injection at 8 and $24 \mathrm{~h}$ intervals. Mechanical nociceptive thresholds were determined by paw withdrawal to application of a series of calibrated von Frey filaments (Stoelting, Wood Dale, IL) to the glabrous surface of the hindpaws. Before testing, animals were acclimatized to the testing area for $30 \mathrm{~min}$. After application of von Frey filaments (0.4-26 g) with enough force to cause buckling of the filament, a modification of the up-down method of Dixon (1980) was used to determine the value at which paw withdrawal occurred $50 \%$ of the time (Chaplan et al., 1994), interpreted to be the mechanical nociceptive threshold.

After acclimation to the test chamber, thermal nociceptive thresholds were assessed by measuring the latency of paw withdrawal in response to a radiant heat source (Dirig et al., 1997). Animals were placed in Plexiglas boxes on an elevated glass plate $\left(37^{\circ} \mathrm{C}\right)$ under which a radiant heat source (5.14 amps) was applied to the glabrous surface of the paw through the glass plate. The heat source was turned off automatically by a photocell on limb-lift, allowing the measurement of paw withdrawal latency. If no response was detected, the heat source was automatically shut off at $20 \mathrm{~s}$. Three minutes were allowed between each trial, and four trials were averaged for each limb.

Statistical analysis. Data were evaluated at an $\alpha$ level of 0.05 by twotailed analyses. Within-group measures were tested for significance using one-way ANOVA, followed by Bonferroni's post hoc analysis. Pairwise comparisons were performed with either the paired Student's $t$ test or the two-sample Student's $t$ test. Linear relationships were assessed using Pearson's correlation test. Data management and statistical analyses were performed with Jandel SigmaStat (version 1.0) and graphed using Jandel SigmaPlot (version 7.0) as mean \pm SD.

\section{Results}

\section{SCI-induced microglial activation in the VPL correlates with lowered nociceptive thresholds}

Immunostaining with antibodies against $\mathrm{Cd} 11 \mathrm{~b} / \mathrm{c}$ revealed the presence of microglia in the VPL (identified in Fig. 1a) of both intact and SCI animals ( $n=4$ /group/time point). Resting microglia in intact animals (Fig. 1b) displayed small compact somata bearing long thin ramified processes and were the predominant morphotype. After SCI, activated microglia exhibited marked cellular hypertrophy and retraction of processes, which became progressively more pronounced by 4 weeks in the VPL (Fig. $1 c-f$ ). We observed no signs of astroglial activation in the VPL after SCI (data not shown). As measured by percentage of field analysis ( $n=4$ sections/animal), microglial activation was not observed in the adjacent VPM nucleus (mean, $46.6 \pm 8.1$ arbitrary units) or Rt nucleus (mean, $46.5 \pm 7.9$ ) after SCI (Fig. $1 g$ ). Significant microglial activation in the VPL was observed starting at 2 weeks (71.2 $\pm 13.3 ; p=0.02)$ after SCI compared with sham-operated 
Table 1. Enzyme immunoassay of microglial activators and proinflammatory cytokines in the ventrobasal thalamus in intact animals and in animals 4 weeks after T9 SCI

\begin{tabular}{|c|c|c|c|c|c|c|c|}
\hline \multirow[b]{2}{*}{ Group } & \multicolumn{7}{|l|}{ Analyte } \\
\hline & $\begin{array}{l}\text { Fractalkine } \\
\text { (CCL5) }\end{array}$ & MCP-1 (CCL2) & MIP-1 $\alpha$ & RANTES & IL-1 $\beta$ & IL-6 & $\operatorname{TNF} \alpha$ \\
\hline $\operatorname{Intact}(n=8)$ & $352.5 \pm 14.6$ & $50.8 \pm 11.9$ & $1.3 \pm 0.2$ & $25.2 \pm 6.8$ & $66.1 \pm 13.3$ & $145.7 \pm 7.6$ & $63.5 \pm 8.3$ \\
\hline $\mathrm{SCl}(n=9)$ & $307.7 \pm 9.3$ & $55.6 \pm 5.3$ & $1.6 \pm 0.4$ & $23.5 \pm 4.9$ & $69.3 \pm 15.2$ & $182.9 \pm 13.3(p=0.005$ vs intact $)$ & $67.5 \pm 17.6$ \\
\hline
\end{tabular}

Data represent mean $\pm S D$ values (in picograms per milligram of tissue).

animals (mean, $43.9 \pm 6.5$ ), and at 4 weeks $(108.6 \pm 7.3)$ correlated with reductions in mechanical nociceptive thresholds $(n=6$ animals/group) in SCI animals (mean, $3.8 \pm 1.6$ g; $y=-0.05 x, r^{2}=0.46, p=$ 0.005) (Fig. 1h). For comparison, in shamoperated animals, mechanical paw withdrawal thresholds were $22.7 \pm 3.4 \mathrm{~g}$.

Table 1 lists the results from enzyme immunoassay of microglial activators and proinflammatory cytokines in the ventrobasal thalamus in intact animals $(n=8)$, and in animals 4 weeks after T9 SCI $(n=$ 9). Only IL-6 was significantly elevated in the SCI group $(182.9 \pm 13.3 \mathrm{pg} / \mathrm{mg}$ tissue; $p=0.005)$ compared with intact (145.7 \pm $7.6 \mathrm{pg} / \mathrm{mg}$ tissue).

\section{Multiple locations in the spinal cord regulate CCL21 levels in the VPL after SCI}

A low level of CCL21 signal is present in sham-operated animals (Fig. 2a). At 4 weeks after SCI, CCL21 signal is increased in lumbar dorsal horn neurons (Fig. 2b), which is eliminated by preabsorption with CCL21 (Fig. 2c). CCL21 signal colocalizes with large diameter (12 $\mu \mathrm{m}$ diameter or greater) NeuN-positive (Fig. 2d,e) (19.5 \pm $3.9 \%$ of NeuN-positive cells) and glutamate-positive (Fig. 2f,g) cells. At these time points, EIA analysis revealed significantly elevated dorsal horn tissue levels of CCL21 in the T9 $(75.3 \pm 22.7 \mathrm{pg} /$ mg; $n=6 ; p=0.003)$ and L4 (39.0 \pm 11.3 $\mathrm{pg} / \mathrm{mg} ; n=6 ; p=0.001)$ segments 4 weeks after SCI, when compared with T9 $(8.3 \pm$ $3.5 \mathrm{pg} / \mathrm{mg})$ and L4 (12.3 $\pm 2.1 \mathrm{pg} / \mathrm{mg}) \mathrm{seg}-$ ments in sham-operated animals (Fig. $2 h$ ).

In the VPL of intact animals (Fig. 3a), low levels of CCL21 signal were observed in cell bodies exhibiting neuronal morphologies. After SCI, an increase in CCL21 signal was observed in the VPL within neuronal cell bodies and parenchyma (Fig. 3b). CCl21 signal remained low in adjacent structures such as the VPM and Rt, and the internal capsule.

To ascertain whether increased tissue levels of CCL21 after SCI could be triggered by increased afferent barrage from STT neurons at the site of injury, or from the lumbar enlargement, which serves as the site of origin of a large population of nociceptive afferent fibers projecting to the VPL, we analyzed CCL2 1 levels after application of $2 \%$ lidocaine and subsequent transection of the spinal cord at T1 or L1 spinal segments (Fig. 3c). After bars indicate SD.
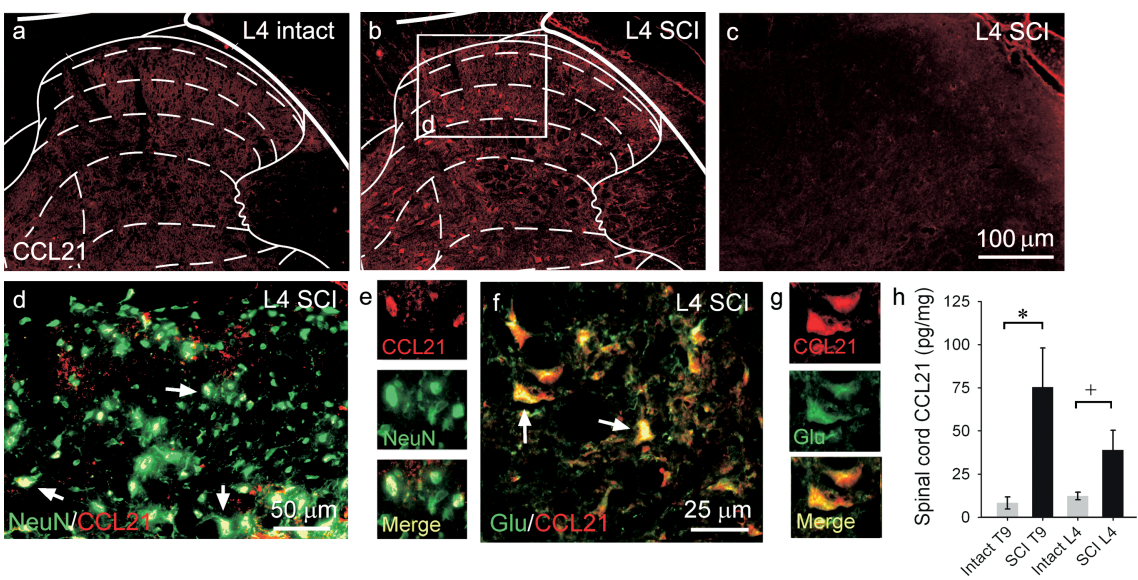

Figure 2. CCL21 upregulation in lumbar dorsal horn neurons after SCI. $\boldsymbol{a}$, In sham-operated animals, CCL21 signal was low within lumbar dorsal horn neurons. $\boldsymbol{b}$, In tissue collected 4 weeks after SCl, CCL21 signal was increased in dorsal horn neurons within laminae I-V (Paxinos and Watson, 1998). c, CCL21 signal was eliminated with preabsorption antibody treatment after SCI. $\boldsymbol{d}, \boldsymbol{e}$, After SCl, CCL21 signal colocalized with NeuN, a marker of neurons (d), but only in a subset of cells (arrows) (e).f, $\boldsymbol{g}$, CCL21 also colocalized with glutamate. $\boldsymbol{h}$, Enzyme immunoassay revealed significantly elevated dorsal horn tissue levels of CCL21 in the T9 $\left({ }^{*} p<0.05\right)$ and L4 ( $\left.{ }^{+} p<0.05\right)$ segments 4 weeks after SCl, compared with T9 and L4 segments of sham-operated animals. Error
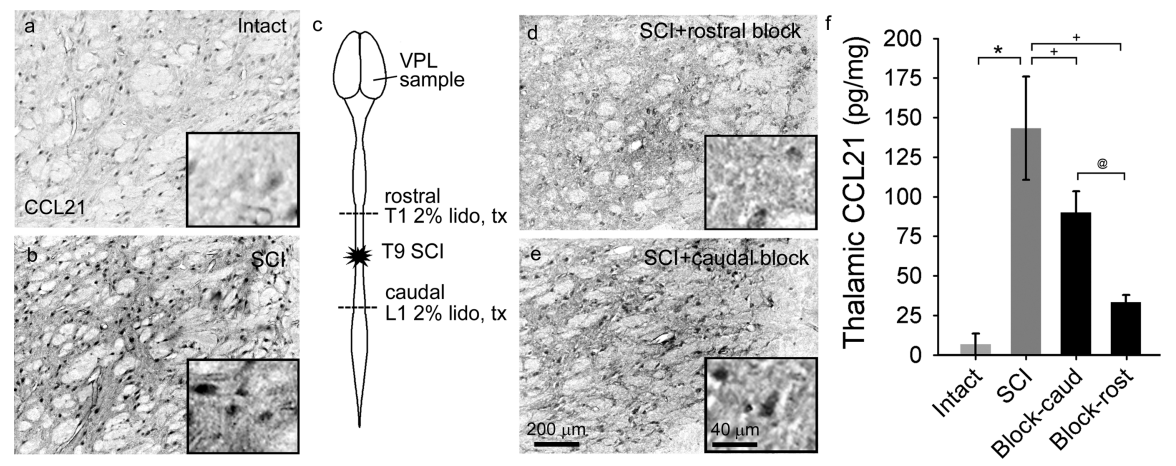

Figure 3. CCL21 content in the VPL after SCl is reduced by spinal blockade. $\boldsymbol{a}, \boldsymbol{b}$, In intact animals $\boldsymbol{a}$, levels of CCL21 signal were low, whereas after $\mathrm{SCl}(\boldsymbol{b})$ levels were higher in parenchyma and neuronal cell bodies. $\boldsymbol{c}, \boldsymbol{e}$, Spinal cord interruption with $2 \%$ lidocaine followed by surgical transection at either T1 or L1 spinal segments (c) resulted in decreases in CCL21 signal after interruption of spinal afferent barrage $(\boldsymbol{d}, \boldsymbol{e}) . \boldsymbol{f}$, Quantification of $\mathrm{CC} 21$ levels in the ventrobasal complex of the thalamus revealed a significant increase after $\mathrm{SCl}$ when compared with intact animals $\left({ }^{*} p<0.05\right)$, which was significantly $\left({ }^{+} p<0.05\right)$ attenuated after rostral (T1) or caudal (L1) spinal blockade. Rostral blockade was significantly more effective than caudal block in reducing CCL21 levels $\left({ }^{@} p<0.05\right)$. Error bars indicate SD.

rostral blockade at T1 (Fig. 3d), CCL21 signal was markedly reduced in the VPL, whereas after blockade caudal to the impact site (but rostral to the lumbar enlargement) at L1, CCL21 signal was only slightly reduced (Fig. $3 e$ ).

Tissue levels of CCL21 in the ventrobasal complex of the thalamus, measured by EIA (Fig. $3 f$ ), showed a significant increase in CCL21 4 weeks after SCI $(143.3 \pm 32.6 \mathrm{pg} / \mathrm{mg}$ tissue; $n=9 ; p=$ $0.001)$ compared with intact animals $(6.7 \pm 6.9 \mathrm{pg} / \mathrm{mg} ; n=8)$. Rostral spinal blockade at T1 $(33.4 \pm 4.7 \mathrm{pg} / \mathrm{mg} ; n=4 ; p=$ 


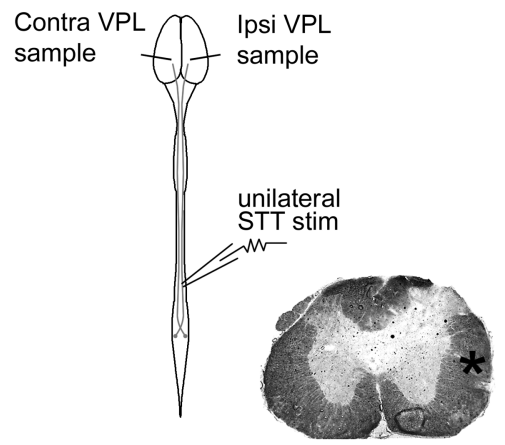

b

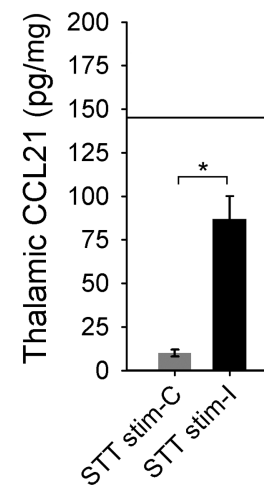

Figure 4. Unilateral stimulation of the STT elicits increases in thalamic CCL21 in intact animals. $\boldsymbol{a}, \boldsymbol{b}$, Electrical stimulation of the ventrolateral funiculus $(\boldsymbol{a})$ resulted in an increase in CCL21 levels within the ventrobasal thalamus on the ipsilateral side, but not the contralateral side $\left[{ }^{*} p<0.05\right.$ ipsilateral (I) vs contralateral (C) sides], measured by enzyme immunoassay (b). The horizontal line indicates CCL21 levels after SCI. The site of stimulation is shown (asterisk). Error bars indicate SD.

$0.005)$ and caudal spinal blockade at L1 $(90.0 \pm 13.3 \mathrm{pg} / \mathrm{mg} ; n=$ $4 ; p=0.007)$ significantly reduced thalamic CCL21 levels compared with the SCI group; however, rostral block was more effective in reducing CCL21 than caudal block.

Effect of STT stimulation on CCL21 levels in the thalamus To determine whether high-frequency stimulation of the STT can induce an increase in CCL21 within the thalamus after SCI, we performed supramaximal electrical stimulation of the STT in intact animals $(n=8)$ (Fig. 4). The frequency was equivalent to the firing frequency of STT units measured after SCI (Hains et al., 2003). Unilateral STT stimulation at L1 resulted in a significant increase in thalamic levels of CCL21 on the ipsilateral side $(86.6 \pm 13.5 \mathrm{pg} / \mathrm{mg}$ tissue; $p=0.003)$ as measured by enzyme immunoassay $(n=4) 20-25 \mathrm{~min}$ after stimulation. Contralateral levels $(10.2 \pm 2.0 \mathrm{pg} / \mathrm{mg})$ were not different from levels observed in intact animals (Fig. $3 f$ ).

\section{Intra-VPL injection of CCL21 transiently induces microglial} activation and pain-related behaviors

Direct injections of rmCCL2 1 into the VPL of intact animals $(n=$ 4 animals/time point) (Fig. $5 a$ ) led to activation of local microglia. Representative images from an intact animal (Fig. 5b) immunostained for $\mathrm{Cd} 1 \mathrm{~b} / \mathrm{c}$ show typical resting morphologies. In contrast, as soon as $4 \mathrm{~h}$ after CCL21 injection (Fig. $5 c$ ), microglia exhibited morphologies consistent with the early phases of activation, whereby somal compartments began to hypertrophy, and secondary and tertiary cellular process retracted. Morphological activation peaked at $8 \mathrm{~h}$ after injection (Fig. $5 f$ ), and by $48 \mathrm{~h}$ returned to baseline activation status (Fig. 5i). Analysis of percentage of $\mathrm{Cd} 11 \mathrm{~b} / \mathrm{c}$ field area revealed significant increases in activation after rmCCL21 injection compared with aCSF vehicle (mean, $49.7 \pm 9.8$ arbitrary units) at the $4 \mathrm{~h}(89.3 \pm 16.1 ; p=$ $0.002), 8 \mathrm{~h}(96.9 \pm 22.9 ; p=0.001), 12 \mathrm{~h}(77.8 \pm 12.5 ; p=0.002)$, and $24 \mathrm{~h}(74.5 \pm 15.5 ; p=0.005)$ time points (Fig. 5j). In a separate experiment, at $8 \mathrm{~h}$ after injection of vehicle, rmCCL21, or rmCCL2 1 plus minocycline ( $n=8$ animals/group), mechanical and thermal nociceptive thresholds were tested (Fig. $5 k$ ). Paw withdrawal thresholds to stimulation of the glabrous surface of the paw with a graded series of calibrated von Frey filaments were unchanged in animals receiving injections of vehicle (21.3 \pm $1.5 \mathrm{~g})$, which were equivalent to intact animals $(22.7 \pm 2.3 \mathrm{~g})$

(data not shown). In contrast, mechanical thresholds in animals receiving rmCCL2 1 were significantly decreased $(2.7 \pm 0.9 \mathrm{~g} ; p=$ 0.001 ) compared with vehicle, implicating CCL21 in the development of mechanical allodynia. The pronociceptive effects of rmCCL21 were prevented by simultaneous delivery of the microglial inhibitor minocycline (18.6 $\pm 2.4 \mathrm{~g})$. Paw withdrawal latencies to thermal stimulation of the hindpaw with a radiant heat source did not reveal a change in vehicle-injected animals (9.8 \pm $1.3 \mathrm{~s}$; equivalent to $\left.42.1^{\circ} \mathrm{C}\right)$ compared with intact animals $(10.3 \pm$ $1.9 \mathrm{~s} ; 42.6^{\circ} \mathrm{C}$ ) (data not shown). rmCCL21 injections, however, resulted in significantly reduced paw withdrawal latencies to thermal stimulation $\left(4.4 \pm 1.2 \mathrm{~s} ; 38.2^{\circ} \mathrm{C} ; p=0.006\right)$, compared with vehicle. Reductions in withdrawal latency caused by rmCCL21 were blocked with minocycline $(9.1 \pm 1.9 \mathrm{~s})$.

\section{Neutralization of CCL21 abrogates post-SCI microglial activation, neuronal hyperexcitability, and pain behaviors}

To evaluate the effects of selective inhibition of CCL21 in SCI animals, we directly injected a neutralizing antibody generated against CCL21 ( $\alpha$ CCL21) bilaterally into the VPL at 4 weeks after injury (i.e., at a time when microglial activation in the VPL was robust and correlated to reductions in behavioral nociceptive thresholds). Microglial activation was evaluated at $8 \mathrm{~h}(n=4$ animals) and $24 \mathrm{~h}(n=4$ animals $)$ after injection based on behavioral analysis of pain thresholds, which revealed increases in nociceptive thresholds after $\alpha$ CCL2 1 injection, that peaked at $8 \mathrm{~h}$. Control IgG injections had no effect on microglial activation $8 \mathrm{~h}$ after administration (Fig. 6a). Eight hours after infusion of $\alpha$ CCL21, Cd11b/c staining showed microglia that predominantly exhibited a resting morphotype (Fig. $6 b$ ). At 24 h post- $\alpha$ CCL21, microglia demonstrated a combination of resting and activated states (Fig. 6c). Percentage of field area analysis for $\mathrm{Cd} 11 \mathrm{~b} / \mathrm{c}$ showed a significant microglial deactivation at $8 \mathrm{~h}(44.8 \pm 8.0$ arbitrary units; $p=0.003$ ) in animals that received $\alpha$ CCL2 1 compared with $\operatorname{IgG}(80.6 \pm 5.9)$. At the $24 \mathrm{~h}$ time point, $\mathrm{Cd} 1 \mathrm{lb} / \mathrm{c}$ field area remained significantly reduced for animals receiving $\alpha$ CCL21 (53.7 $\pm 9.4 ; p=0.006)$ compared with IgG (77.4 \pm 7.5$)$. Although we did not achieve the statistical power to demonstrate a significant increase in Cd11b/c field area between the 8 and $24 \mathrm{~h}$ time points for $\alpha \mathrm{CCL} 21$, there was a trend toward significance. In intact animals, intra-VPL injections of $\alpha$ CCL21 did not result in changes in microglial activation status at the $8 \mathrm{~h}(29.1 \pm 5.1)$ or $24 \mathrm{~h}(32.4 \pm 5.3)$ time points. Selective inhibition of activated microglia with intra-VPL injection of minocycline $(n=4)$ also significantly reduced $\mathrm{Cd} 11 \mathrm{~b} / \mathrm{c}$ field area at $8 \mathrm{~h}(15.9 \pm 10.4 ; p=$ $0.009)$ and $24 \mathrm{~h}(39.4 \pm 15.8 ; p=0.01)$ compared with vehicle, with a trend toward a decreased effect at the $24 \mathrm{~h}$ time point (Fig. $6 d$ ). In intact animals, intra-VPL injections of minocycline did not result in changes in microglial activation at the $8 \mathrm{~h}(24.3 \pm$ 3.4) or $24 \mathrm{~h}(23.0 \pm 5.2)$ time points.

SCI resulted in the development of hyperexcitability and sensitization of VPL neurons as shown previously. Extracellular unit recordings obtained from multireceptive VPL units (Fig. 6e) in intact animals ( $n=4$ animals, $4 \mathrm{U} /$ animal) showed low evoked discharge rates in response to stimulation of identified peripheral receptive fields in the hindpaw. Phasic brush (PB) stimulation resulted in a mean discharge rate of $32.8 \pm 2.9 \mathrm{~Hz}$, compressive press $(\mathrm{PR})$ resulted in a mean firing rate of $21.1 \pm 2.3 \mathrm{~Hz}$, and compressive pinch (PI), 24.2 $\pm 1.6 \mathrm{~Hz}$. After SCI and IgG injection ( $n=4$ animals, $4-6 \mathrm{U} /$ animal), evoked discharge rates remained elevated (between 90 and 300\%) to all three natural stimuli, PB $(47.8 \pm 3.9 \mathrm{~Hz}), \mathrm{PR}(42.5 \pm 3.5 \mathrm{~Hz})$, and PI $(57.3 \pm 3.6$ $\mathrm{Hz})$, levels consistent with previous reports of post-SCI thalamic 

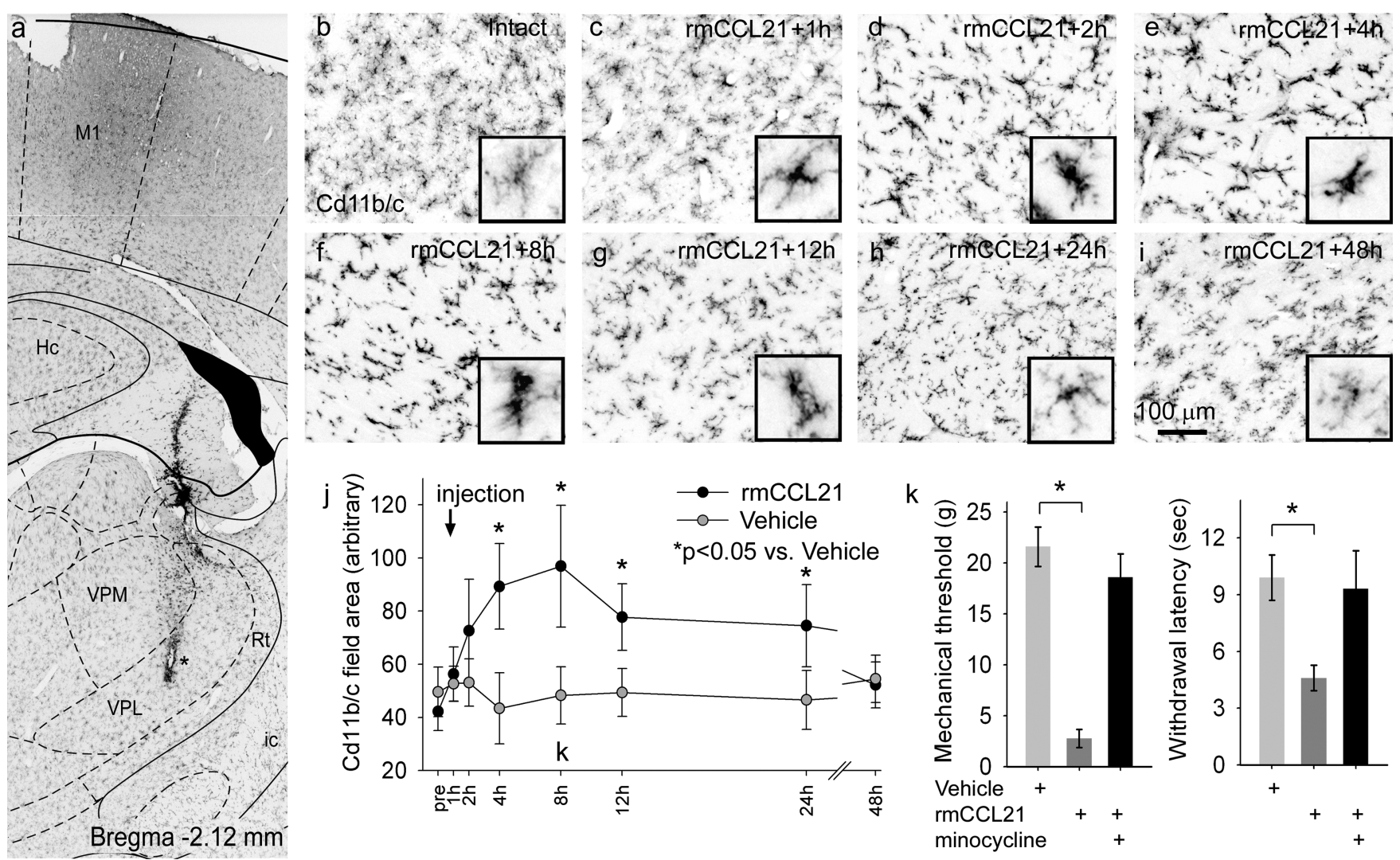

Figure 5. Intra-VPL injection of rmCCL21 elicits microglial activation and pain-related behaviors. $\boldsymbol{a}$, In intact animals, rmCCL21 was stereotaxically injected into the VPL bilaterally. M1, Motor cortex; $\mathrm{Hc}$, hippocampus. $\boldsymbol{b}$, In intact animals, Cd11b/c staining identified microglia exhibiting the resting morphology. $\mathbf{c}-\boldsymbol{i}$, In rmCCL21-receiving animals (c-i), microglia demonstrated a transient activation, which peaked at $8 \mathrm{~h}$ after injection $(\boldsymbol{f})$. $\boldsymbol{j}$, This activation was significant compared with animals receiving vehicle at $4-24 \mathrm{~h} . \boldsymbol{k}$, At the peak of microglial activation $(8 \mathrm{~h})$, mechanical and thermal nociceptive thresholds on the hindpaw were evaluated. When compared with vehicle, rmCCL21 produced a strong lowering of mechanical nociceptive thresholds $\left({ }^{*} p<0.05\right)$. Simultaneous delivery of the microglial inhibitor minocycline partially blocked this reduction in mechanical threshold. Similarly, withdrawal latencies to radiant thermal stimulation were reduced with rmCCL21 $\left({ }^{*} p<0.05\right)$, whereas coadministration of minocycline attenuated this effect. Error bars indicate SD.

firing activity recorded by us. Intra-VPL injection of $\alpha$ CCL21 ( $n=4$ animals, $4-6 \mathrm{U} /$ animal) attenuated the evoked hyperexcitability and resulted in significantly decreased firing rates to BR $(36.3 \pm 2.1 \mathrm{~Hz} ; p=0.04), \mathrm{PR}(24.6 \pm 2.5 \mathrm{~Hz} ; p=0.02)$, and PI $(31.4 \pm 2.4 \mathrm{~Hz} ; p=0.007)$ at the $8 \mathrm{~h}$ time point compared with IgG (Fig. $6 f$ ). $\alpha$ CCL21 did not have an appreciable effect on the rate of spontaneous background (or possibly burst) firing compared with SCI animals, which is required to occur above a certain rate. Our data do not permit us to draw conclusions regarding the relationship of CCL21 levels to the discharge rate of VPL units.

After SCI, mechanical and thermal nociceptive thresholds in response to hindpaw receptive field stimulation with von Frey filaments or radiant thermal stimulus were decreased $(n=6-8$ animals/group). Mechanical thresholds (Fig. $6 g$ ) were significantly reduced (mean, $3.1 \pm 1.9 \mathrm{~g} ; p=0.006$ ) compared with intact animals $(21.2 \pm 1.6 \mathrm{~g})$. By $4 \mathrm{~h}$ after injection (data not shown), $\alpha$ CCL21 resulted in a partial restoration of mechanical thresholds, which peaked at $8 \mathrm{~h}(11.0 \pm 2.9 \mathrm{~g} ; p=0.01)$ compared with IgG control, but by $24 \mathrm{~h}$ thresholds had returned to allodynic levels $(2.6 \pm 0.7 \mathrm{~g})$, and were not different from $\operatorname{IgG}(3.3 \pm 1.2 \mathrm{~g})$. IgG injection did not alter mechanical thresholds (mean, $4.7 \pm$ $1.3 \mathrm{~g}$ ). Mechanical nociceptive thresholds were unchanged in intact animals that received intra-VPL injections of minocycline or $\alpha$ CCL2 1 at $8 \mathrm{~h}(20.1 \pm 1.2$ and $21.3 \pm 1.6$ g, respectively $)$, or $24 \mathrm{~h}$ $(22.8 \pm 2.7$ and $21.8 \pm 2.6$ g, respectively), compared with base- line $(21.3 \pm 1.2$ and $22.9 \pm 1.3$ g, respectively). Paw withdrawal latencies to thermal stimulation (Fig. 6h) were significantly decreased after SCI [mean, $4.5 \pm 1.0$ s (i.e., withdrawal at $38.0^{\circ} \mathrm{C}$ ); $p=0.001]$ compared with intact animals $(11.5 \pm 1.8 \mathrm{~s}$; withdrawal at $43 \cdot 2^{\circ} \mathrm{C}$ ). A significant increase in thermal threshold was observed at $4 \mathrm{~h}$ after injection of $\alpha \mathrm{CCL} 21$. At the $8 \mathrm{~h}$ time point, the peak increase in thermal threshold was achieved with $\alpha$ CCL21 (9.2 $\pm 1.5 \mathrm{~s} ; p=0.003 \mathrm{vs} \mathrm{IgG).} \mathrm{By} 24 \mathrm{~h}$ after injection, latencies for the $\alpha$ CCL2 group returned to hyperalgesic levels $(5.5 \pm 1.3 \mathrm{~s})$ that were not different from IgG-treated SCI animals, which was not altered (mean, $4.7 \pm 1.2 \mathrm{~s}$ ). Similarly, minocycline resulted in a partial restoration of mechanical (15.9 \pm $2.5 \mathrm{~g} ; p=0.007)$ and thermal thresholds $(10.2 \pm 1.8 \mathrm{~s} ; p=0.001)$ after SCI compared with vehicle. Thermal nociceptive thresholds were unchanged in intact animals that received intra-VPL injections of minocycline or $\alpha$ CCL2 1 at $8 \mathrm{~h}\left(11.4 \pm 1.2 \mathrm{~s}, 43.4^{\circ} \mathrm{C}\right.$, and $10.9 \pm 1.8 \mathrm{~s}, 43.2^{\circ} \mathrm{C}$, respectively), or $24 \mathrm{~h}\left(12.6 \pm 1.9 \mathrm{~s}, 43.8^{\circ} \mathrm{C}\right.$, and $11.7 \pm 1.8 \mathrm{~s}, 43.5^{\circ} \mathrm{C}$, respectively), compared with baseline $\left(12.0 \pm 1.4 \mathrm{~s}, 43.6^{\circ} \mathrm{C}\right.$, and $12.8 \pm 1.2 \mathrm{~s}, 43.8^{\circ} \mathrm{C}$, respectively).

\section{Discussion}

SCI leads to changes in excitability of VPL neurons that contribute to neuronal hyperexcitability and chronic pain (Lenz et al., 1989; Weng et al., 2000; Gerke et al., 2003; Hains et al., 2005, 2006; Hubscher and Johnson, 2006). We recently proposed that, after SCI, hyperactive dorsal horn neurons produce an amplified 

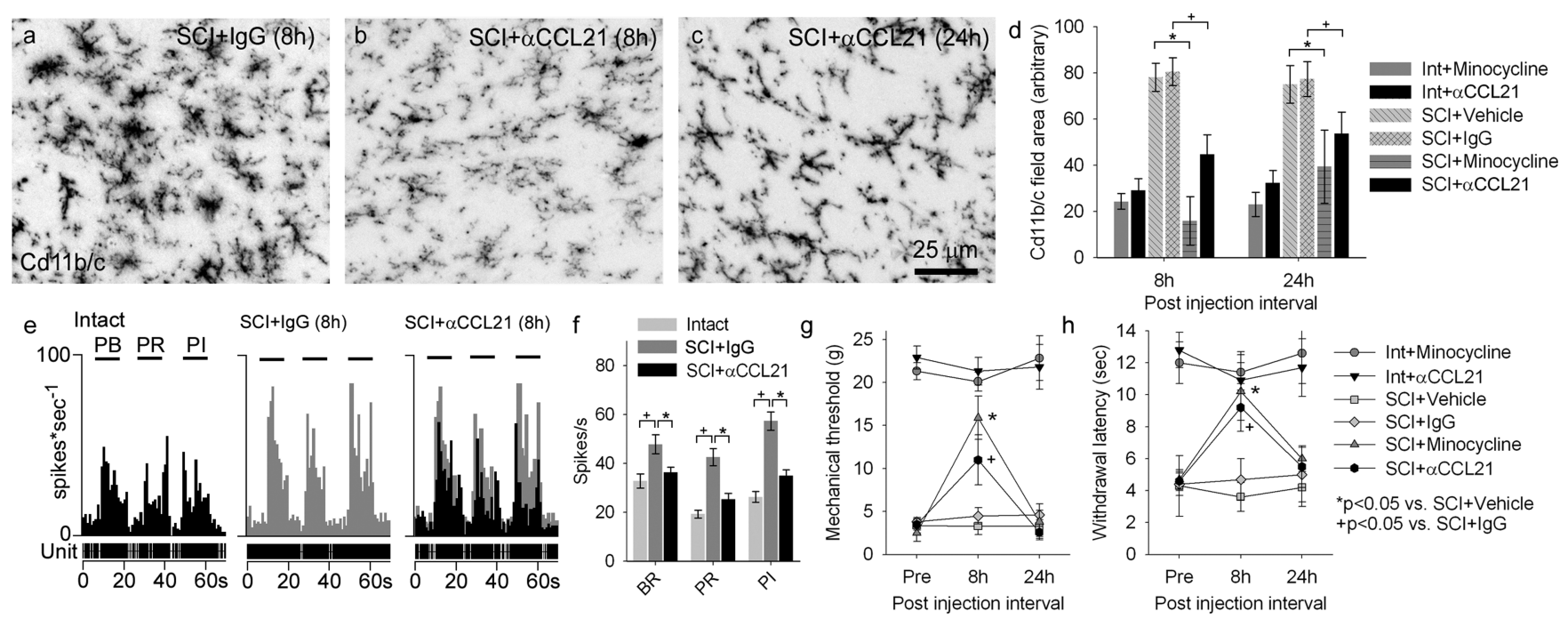

Figure 6. CCL21 neutralization abrogates microglial activation, neuronal hyperexcitability, and pain-related behaviors. $\boldsymbol{a}-\boldsymbol{c}$, Microglial activation in the VPL 4 weeks after SCI was unaffected by IgG injection $(\boldsymbol{a})$, whereas neutralizing antibodies directed against CCL21 $(\alpha \mathrm{CCL} 21 ; \boldsymbol{b})$ robustly deactivated microglia at $8 \mathrm{~h}(\boldsymbol{b})$ and $24 \mathrm{~h}$ (c). $\boldsymbol{d}$, Quantification of $\mathrm{Cd} 11 \mathrm{~b} / \mathrm{c}$ field area revealed significant decreases in microglial activation in animals receiving minocycline $\left({ }^{+} p<0.05\right)$ as well as $\alpha C \mathrm{CL} 21\left({ }^{*} p<0.05\right)$ at both 8 and $24 \mathrm{~h}$ after injection. $\boldsymbol{e}$, Extracellular unit recordings of VPL multireceptive neurons with peripheral receptive fields in the hindpaw from intact animals exhibited low evoked activity in response to PB, PR, and PI stimulation. After SCl, evoked responses were elevated and unaffected by IgG administration at the $8 \mathrm{~h}$ time point. $f$, In contrast, at the $8 \mathrm{~h}$ time point, $\alpha$ CCL21 resulted in reduced hyperexcitability of multireceptive neurons in the VPL, which was significantly decreased compared with $\lg \mathrm{G}$ to all peripheral stimuli. Analysis of mechanical nociceptive thresholds $(\boldsymbol{g})$ demonstrated the development of mechanical allodynia 4 weeks after SCl in all animals before drug delivery. In animals receiving minocycline ( $\left.{ }^{+} p<0.05\right)$ and $\alpha \mathrm{C}\left(21\left(^{*} p<0.05\right)\right.$, paw withdrawal thresholds were significantly elevated compared with vehicle and lgG. $\boldsymbol{h}$, Thermal nociceptive thresholds were also significantly reduced after SCI. Administration of minocycline $\left({ }^{+} p<0.05\right)$ and $\alpha \mathrm{CCL} 21\left({ }^{*} p<0.05\right)$ significantly elevated paw withdrawal latencies compared with vehicle and lgG. Mechanical and thermal thresholds were restored to predrug levels by the $24 \mathrm{~h}$ time point, indicating only a transient relief from mechanical allodynia and thermal hyperalgesia. Error bars indicate SD.

spinal barrage that triggers molecular changes in the VPL (Hains et al., 2005), which could accentuate aberrant nociceptive signaling (Waxman and Hains, 2006). The thalamus is critical in this regard because resultant pathological firing (Hains et al., 2006) more potently activates cortical circuits involved in pain perception through an increased gain at the thalamocortical synapse (Swadlow and Gusev, 2001).

The current study builds on these findings and sheds light on mechanisms underlying the reconfiguration of thalamic nociceptive processing. Our results demonstrate a previously undescribed role for thalamic microglia in post-SCI pain, and provide evidence for remote microglial activation in the thalamus by the chemokine CCL21. CCL21 potently activates resident microglia within the VPL, which in turn pathologically modulate thalamic nociceptive neurons.

Microglial activation in the VPL occurs over the course of several weeks after SCI. However, it is not known whether this correlates with the onset of allodynia and/or hyperalgesia, because before the 4 week time point reliable somatosensory testing is not possible because of slowly resolving locomotor deficits that preclude testing of nociceptive thresholds. It is possible that microglial activation in the VPL is a consequence of spinal hyperexcitability. Alternatively, it may be an autonomous process that is initiated by the injury itself (thus injury dependent). As suggested previously by us (Hains and Waxman, 2006), in the case of central injuries such as SCI, microglial reactivity may differ in mechanism, location, and influence, when compared with peripheral nerve injury where microglial activation is implicated in the initiation phase of pain (Raghavendra et al., 2003; Hua et al., 2005; Ledeboer et al., 2005).

Chemokines activate receptors on macrophages and microglia to trigger migration and activation (White et al., 2005b; Watkins et al., 2007). CCL21 elicits a chemotaxic response by microglia but not monocytes or neutrophils (Gunn et al., 1999), which can be disrupted in CCL21 receptor knock-out mice (Rappert et al., 2004). Diffusible CCL21 binds and activates the CCR7 and CXCR3 receptors expressed by microglia (Soto et al., 1998; Biber et al., 2002; Rappert et al., 2002; Dijkstra et al., 2006). Microglia activated by LPS stimulation in vitro (Dijkstra et al., 2006), in multiple sclerosis lesions (Serafini et al., 2006), and in models of experimental autoimmune encephalomyelitis during symptom onset and progression (Columba-Cabezas et al., 2003; Dijkstra et al., 2006), have been shown to upregulate the CCR7 receptor. Microglia also respond to CCL21 via lower-affinity activation of the CXCR3 receptor (Murphy et al., 2000; Biber et al., 2001; Rappert et al., 2002; Dijkstra et al., 2004). CXCR3 is also expressed by astrocytes and neurons; however, CCL21 is not a functional ligand for CXCR3 in these cells (Biber et al., 2002; de Jong et al., 2005). Given the antigen-presenting capabilities of microglia, expression of these two CCL21 receptors may differ depending on stimuli present in the local microenvironment and/or injury state (Dijkstra et al., 2006). Future work should examine microglial CCL21 receptor populations in naive conditions, after peripheral or central injury, and in association with acute or chronic pain in different nociceptive structures.

There are several possibilities regarding the source of thalamic CCL21: CCL21 released from presynaptic (putative STT) terminals, and/or intrinsic VPL cells. In the first case, CCL21 could be synthesized by nociceptive neurons and by other cells in response to injury (White et al., 2005b). After SCI, CCL21 could be upregulated in the cell bodies of damaged STT neurons, and then transported the VPL. This is predicted by in vitro studies showing that neurons exposed to high concentrations of glutamate [which occurs surrounding the SCI epicenter (McAdoo et al., 1999)] rapidly express and release the chemokine CCL21, and that this CCL21 is packed in vesicles and transported throughout neuro- 
nal processes to reach presynaptic structures (de Jong et al., 2005). This possibility is supported by our data showing increased CCL21 signal in excitatory neurons of the dorsal horn, and in spinal parenchyma at both the T9 and L4 spinal segments after SCI; however, it is not possible to know in our model whether vesicular packaging and transport occurs. Interruption of the spinal afferent barrage at several sites after SCI reduced CCL21 levels in the VPL, with the degree of reduction depending on the location of the spinal block, suggesting that activity within multiple spinal sites can influence CCL21 levels in the VPL, but to different degrees. The rapidity of the reduction in thalamic levels of CCL21 after cord blockade suggests that the spinal cord either directly or indirectly can modulate CCL21 levels. Alternate explanations for this finding are (1) that spinal transection produces a massive barrage of activation in VPL resulting in the local release and degradation of CCL21 causing the decrease in CCL21 as measured by EIA and immunostaining, and/or (2) that rostrally applied lidocaine diffuses through the ventricular system to the VPL, penetrates into the VPL, and effects CCL21 release, although studies of CSF flow dynamics and drug movement make this possibility unlikely (Bernards, 1999). Whether events occurring at the site of injury (T9) or lumbar enlargement (L3-L5) contribute differentially to thalamic microglial activation is not known, but our data suggest that the influence is additive. It is possible that the site of injury may exert a greater influence because en passant STT axons may be damaged by injury-induced events or by intermingling of damaged at-level STT fibers. Moreover, intrathalamic microinjection of CCL21 neutralizing antibodies or the microglial inhibitor minocycline only transiently deactivated microglia (and reversed neuronal hyperexcitability and pain-related behaviors), implicating a persistent activating drive.

In the second case, because electrical stimulation of the STT in intact animals resulted in a rapid increase in CCL21 levels in the thalamus (which would preclude vesicular packaging and transport along the STT), and because CCL21 levels were not completely abolished by cord transection rostral to both the injury site and lumbar enlargement after SCI, it is likely that intrinsic neurons of the VPL produce at least some CCL21. CCL21 signal was observed in cells exhibiting neuronal morphologies within the VPL after injury. An alternate explanation is that some CCL21 remained in presynaptic structures after cord transection. It cannot be determined whether CCL2 1 is released locally by these neurons, possibly as a result of STT stimulation, and/or whether CCL21 is being recycled by these neurons after release from presynaptic structures. Given our data, we hypothesize that increases in thalamic CCL21 after SCI might be dependent on both spinal and local factors, but future experiments should address these issues.

Regardless of the source of the CCL21 increase in the thalamus, our data identify a new neuron-microglia signaling mechanism by which microglia can be activated in the context of nervous system injuries that produce pain. Thus far, fractalkine and MCP-1 signaling mechanisms have been implicated in the initiation of pain. The chemokine fractalkine [CX3CL1 (C-X3-C motif ligand 1)] is expressed in sensory afferents and intrinsic spinal cord neurons, and its receptor (CX3CR1) is expressed primarily by microglia (Verge et al., 2004). Fractalkine is a potent modulator that activates microglia after peripheral nerve injury and contributes to the induction phase of pain in the spinal cord (Milligan et al., 2004). MCP-1 (CCL2) is upregulated in damaged dorsal root ganglion neurons (White et al., 2005a), and can be transported to sensory terminals in the spinal cord where it acti- vates microglia (Zhang and De Koninck, 2006). Through biochemical analysis, we did not observe elevations in fractalkine or MCP-1 levels within the ventrobasal thalamus of animal exhibiting chronic pain VPL at a time when microglia were activated. Nor did we measure increases in the potential microglial activators RANTES (CCL5) or MIP- $1 \alpha$.

After SCI, levels of the proinflammatory cytokine IL-6 were elevated in the thalamus. The precise role of IL- 6 in this case is not known, however, given that IL-6 possesses a dual role as a microglial activator as well as a neuromodulator (produced by microglia) (Milligan et al., 2005; Schoeniger-Skinner et al., 2007). That IL- $1 \beta$ and TNF $\alpha$, which have been implicated in microglia-neuron pain signaling (Milligan et al., 2001; Ledeboer et al., 2005), were not significantly elevated in the thalamus after SCI does not lessen the potential influence of microglia on neuronal excitability. It is possible that microglia signal neurons through different cytokines at acute and chronic time points after SCI, and at locations distant to the site of injury. We have recently shown that after SCI microglia use $\mathrm{PGE}_{2}$ as a microglia-neuron signaling molecule, which is regulated by pERK1/2, to induce hyperexcitability of lumbar dorsal horn neurons (Zhao et al., 2007). $\mathrm{PGE}_{2}$ may also act as a microglia-neuron signal in the VPL as well.

In summary, these experiments identify a mechanism whereby SCI triggers a remote secondary pathology in the VPL that specifically contributes to the persistent amplification of abnormal nociceptive signals and chronic pain.

\section{References}

Bernards CM (1999) Epidural and intrathecal drug movement. In: Spinal drug delivery (Yaksh TL, ed), pp 239-252. Amsterdam: Elsevier.

Biber K, Sauter A, Brouwer N, Copray SC, Boddeke HW (2001) Ischemiainduced neuronal expression of the microglia attracting chemokine secondary lymphoid-tissue chemokine (SLC). Glia 34:121-133.

Biber K, Dijkstra I, Trebst C, De Groot CJA, Ransohoff RM, Boddeke HWGM (2002) Functional expression of CXCR3 in cultured mouse and human astrocytes and microglia. Neuroscience 112:487-497.

Carbonell WS, Murase SI, Horwitz AF, Mandell JW (2005) Infiltrative microgliosis: activation and long-distance migration of subependymal microglia following periventricular insults. J Neuroinflammation 2:5.

Chang HT (2007) Subacute human spinal cord contusion: few lymphocytes and many macrophages. Spinal Cord 45:174-182.

Chaplan SR, Bach FW, Pogrel JW, Chung JM, Yaksh TL (1994) Quantitative assessment of tactile allodynia in the rat paw. J Neurosci Methods 53:55-63.

Columba-Cabezas S, Serafini B, Ambrosini E, Aloisi F (2003) Lymphoid chemokines CCL19 and CCL21 are expressed in the central nervous system during experimental autoimmune encephalomyelitis: implications for the maintenance of chronic neuroinflammation. Brain Pathol $13: 38-51$.

Coyle DE (1998) Partial peripheral nerve injury leads to activation of astroglia and microglia which parallels the development of allodynic behavior. Glia 23:75-83.

Crown ED, Ye Z, Johnson KM, Xu GY, McAdoo DJ, Hulsebosch CE (2006) Increases in the activated forms of ERK 1/2, p38 MAPK, and CREB are correlated with the expression of at-level mechanical allodynia following spinal cord injury. Exp Neurol 199:397-407.

de Jong EK, Dijkstra IM, Hensens M, Brouwer N, van Amerongen M, Liem RS, Boddeke HW, Biber K (2005) Vesicle-mediated transport and release of CCL21 in endangered neurons: a possible explanation for microglia activation remote from a primary lesion. J Neurosci 25:7548-7557.

DeLeo JA, Tawfik VL, LaCroix-Fralish ML (2006) The tetrapartite synapse: path to CNS sensitization and chronic pain. Pain 122:17-21.

Dijkstra IM, de Haas AH, Brouwer N, Boddeke HW, Biber K (2006) Challenge with innate and protein antigens induces CCR7 expression by microglia in vitro and in vivo. Glia 54:861-872.

Dijkstra M, Hulshof S, van der Valk P, Boddeke HWGM, Biber K (2004) Functional activity of human adult microglia in response to CCL21. J Immunol 172:2744-2747. 
Dirig DM, Salami A, Rathbun ML, Ozaki GT, Yaksh TL (1997) Characterization of variables defining hindpaw withdrawal latency evoked by radiant thermal stimuli. J Neurosci Methods 76:183-191.

Dixon WJ (1980) Efficient analysis of experimental observations. Annu Rev Pharmacol Toxicol 20:441-462.

Elzaouk L, Pavlovic J, Moelling K (2006) Analysis of antitumor activity elicited by vaccination with combinations of interleukin-12 DNA with gp100 DNA or the chemokine CCL21 in vivo. Hum Gene Ther 17: 859-870.

Fu KY, Light AR, Matsushima GK, Maixner W (1999) Microglial reactions after subcutaneous formalin injection into the rat hind paw. Brain Res 825:59-67.

Gerke MB, Duggan AW, Xu L, Siddall PJ (2003) Thalamic neuronal activity in rats with mechanical allodynia following contusive spinal cord injury. Neuroscience 117:715-722.

Gruner JA (1992) A monitored confusion model of spinal cord injury in the rat. J Neurotrauma 9:123-128.

Gunn MD, Kyuwa S, Tam C, Kakiuchi T, Matsuzawa A, Williams LT, Nakano H (1999) Mice lacking expression of secondary lymphoid organ chemokine have defects in lymphocyte homing and dendritic cell localization. J Exp Med 189:451-460.

Hains BC, Waxman SG (2006) Activated microglia contribute to the maintenance of chronic pain after spinal cord injury. J Neurosci 26:4308-4317.

Hains BC, Klein JP, Saab CY, Craner MJ, Black JA, Waxman SG (2003) Upregulation of sodium channel Nav1.3 and functional involvement in neuronal hyperexcitability associated with central neuropathic pain after spinal cord injury. J Neurosci 23:8881-8892.

Hains BC, Saab CY, Waxman SG (2005) Changes in electrophysiological properties and sodium channel Nav1.3 expression in thalamic neurons after spinal cord injury. Brain 128:2359-2371.

Hains BC, Saab CY, Waxman SG (2006) Alterations in burst firing of thalamic VPL neurons and reversal by Nav1.3 antisense after spinal cord injury. J Neurophys 95:3343-3352.

Hua XY, Svensson CI, Matsui T, Fitzsimmons B, Yaksh TL, Webb M (2005) Intrathecal minocycline attenuates peripheral inflammation-induced hyperalgesia by inhibiting p38 MAPK in spinal microglia. Eur J Neurosci 22:2431-2440.

Hubscher CH, Johnson RD (2006) Chronic spinal cord injury induced changes in the responses of thalamic neurons. Exp Neurol 197:177-188.

Ji RR, Strichartz G (2004) Cell signaling and the genesis of neuropathic pain. Science STKE 252:re14.

Jin SX, Zhuang ZY, Woolf CJ, Ji RR (2003) p38 mitogen-activated protein kinase is activated after a spinal nerve ligation in spinal cord microglia and dorsal root ganglion neurons and contributes to the generation of neuropathic pain. J Neurosci 23:4017-4022.

Jones EG (1998) Viewpoint: the core and matrix of thalamic organization. Neuroscience 85:331-345.

Koyama S, Katayama Y, Maejima S, Hirayama T, Fujii M, Tsubokawa T (1993) Thalamic neuronal hyperactivity following transection of the spinothalamic tract in the cat: involvement of $N$-methyl-D-aspartate receptor. Brain Res 612:345-350.

Kurpius D, Wilson N, Fuller L, Hoffman A, Dailey ME (2006) Early activation, motility, and homing of neonatal microglia to injured neurons does not require protein synthesis. Glia 54:58-70.

Ledeboer A, Sloane EM, Milligan ED, Frank MG, Mahony JH, Maier SF, Watkins LR (2005) Minocycline attenuates mechanical allodynia and proinflammatory cytokine expression in rat models of pain facilitation. Pain 115:71-83.

Lenz FA, Kwan HC, Dostrovsky JO, Tasker RR (1989) Characteristics of the bursting pattern of action potentials that occurs in the thalamus of patients with central pain. Brain Res 496:357-360.

Liu C, Ueno T, Kuse S, Saito F, Nitta T, Piali L, Nakano H, Kakiuchi T, Lipp M, Hollander GA, Takahama Y (2005) The role of CCL21 in recruitment of T-precursor cells to fetal thymi. Blood 105:31-39.

Marchand F, Perretti M, McMahon SB (2005) Role of the immune system in chronic pain. Nat Rev Neurosci 6:521-532.

Martin RJ, Apkarian AV, Hodge CJ (1990) Ventrolateral and dorsolateral ascending spinal cord pathway influence on thalamic nociception in cat. J Neurophysiol 64:1400-1412.
McAdoo DJ, Xu GY, Robak G, Hughes MG (1999) Changes in amino acid concentrations over time and space around an impact injury and their diffusion through the rat spinal cord. Exp Neurol 159:538-544.

Milligan E, Zapata V, Schoeniger D, Chacur M, Green P, Poole S, Martin D, Maier SF, Watkins LR (2005) An initial investigation of spinal mechanisms underlying pain enhancement induced by fractalkine, a neuronally released chemokine. Eur J Neurosci 22:2775-2782.

Milligan ED, O'Connor KA, Nguyen KT, Armstrong CB, Twining C, Gaykema RP, Holguin A, Martin D, Maier SF, Watkins LR (2001) Intrathecal HIV-1 envelope glycoprotein gp120 induces enhanced pain states mediated by spinal cord proinflammatory cytokines. J Neurosci 21:2808-2819.

Milligan ED, Zapata V, Chacur M, Schoeniger D, Biedenkapp J, O'Connor KA, Verge GM, Chapman G, Green P, Foster AC, Naeve GS, Maier SF, Watkins LR (2004) Evidence that exogenous and endogenous fractalkine can induce spinal nociceptive facilitation in rats. Eur J Neurosci 20:2294-2302.

Moalem G, Tracey DJ (2006) Immune and inflammatory mechanisms in neuropathic pain. Brain Res Rev 51:240-264.

Murphy PM, Baggiolini M, Charo IF, Hebert CA, Horuk R, Matsushima K, Miller LH, Oppenheim JJ, Power CA (2000) International union of pharmacology. XXII. Nomenclature for chemokine receptors. Pharmacol Rev 52:145-176.

Nesic O, Lee J, Johnson KM, Ye Z, Xu GY, Unabia GC, Wood TG, McAdoo DJ, Westlund KN, Hulsebosch CE, Perez-Polo JR (2005) Transcriptional profiling of spinal cord injury-induced central neuropathic pain. J Neurochem 95:998-1014.

Pattany PM, Yezierski RP, Widerstrom-Noga EG, Bowen BC, MartinezArizala A, Garcia BR, Quencer RM (2002) Proton magnetic resonance spectroscopy of the thalamus in patients with chronic neuropathic pain after spinal cord injury. AJNR Am J Neuroradiol 23:901-905.

Paxinos G, Watson C (1998) The rat brain in stereotaxic coordinates, Ed 4. San Diego: Academic.

Popovich PG, Wei P, Stokes BT (1997) Cellular inflammatory response after spinal cord injury in Sprague-Dawley and Lewis rats. J Comp Neurol 377:443-464.

Raghavendra V, Tanga F, DeLeo JA (2003) Inhibition of microglial activation attenuates the development but not existing hypersensitivity in a rat model of neuropathy. J Pharmacol Exp Ther 306:624-630.

Rappert A, Biber K, Nolte C, Lipp M, Schubel A, Lu B, Gerard NP, Gerard C, Boddeke HW, Kettenmann H (2002) Secondary lymphoid tissue chemokine (CCL21) activates CXCR3 to trigger a $\mathrm{Cl}^{-}$current and chemotaxis in murine microglia. J Immunol 168:3221-3226.

Rappert A, Bechmann I, Pivneva T, Mahlo J, Biber K, Nolte C, Kovac AD, Gerard C, Boddeke HW, Nitsch R, Kettenmann H (2004) CXCR23dependent microglial recruitment is essential for dendrite loss after brain lesion. J Neurosci 24:8500-8509.

Schoeniger-Skinner DK, Ledeboer A, Frank MG, Milligan ED, Poole S, Martin D, Maier SF, Watkins LR (2007) Interleukin-6 mediates lowthreshold mechanical allodynia induced by intrathecal HIV-1 envelope glycoprotein gp120. Brain Behav Immun 21:660-667.

Serafini B, Rosicarelli B, Magliozzi R, Stigliano E, Capello E, Mancardi GL, Aloisi F (2006) Dendritic cells in multiple sclerosis lesions: maturation stage, myelin uptake, and interaction with proliferating $\mathrm{T}$ cells. J Neuropathol Exp Neurol 65:124-141.

Soto H, Wang W, Strieter RM, Copeland NG, Gilbert DJ, Jenkins NA, Hedrick J, Zlotnik A (1998) The CC chemokine 6Ckine binds the CXC chemokine receptor CXCR3. Proc Natl Acad Sci USA 95: $8205-8210$.

Sroga JM, Jones TB, Kigerl KA, McGaughy VM, Popovich PG (2003) Rats and mice exhibit distinct inflammatory reactions after spinal cord injury. J Comp Neurol 462:223-240.

Swadlow HA, Gusev AG (2001) The impact of "bursting" thalamic impulses at a neocortical synapse. Nat Neurosci 4:402-408.

Tsuda M, Inoue K, Salter MW (2005) Neuropathic pain and spinal microglia: a big problem from molecules in "small" glia. Trends Neurosci 28:101-107.

Verge GM, Milligan ED, Maier SF, Watkins LR, Naeve GS, Foster AC (2004) Fractalkine (CX3CL1) and fractalkine receptor (CX3CR1) distribution in spinal cord and dorsal root ganglia under basal and neuropathic pain conditions. Eur J Neurosci 20:1150-1160. 
Watkins LR, Milligan ED, Maier SF (2001) Glial activation: a driving force for pathological pain. Trends Neurosci 24:450-455.

Watkins LR, Hutchinson MR, Ledeboer A, Wieseler-Frank J, Milligan ED, Maier SF (2007) Glia as the "bad guys": implications for improving clinical pain control and the clinical utility of opioids. Brain Behav Immun 21:131-146.

Waxman SG, Hains BC (2006) Fire and phantoms after spinal cord injury: $\mathrm{Na}^{+}$channels and central pain. Trends Neurosci 29:207-215.

Weng HR, Lee JI, Lenz FA, Schwartz A, Vierck C, Rowland L, Dougherty PM (2000) Functional plasticity in primate somatosensory thalamus following chronic lesion of the ventral lateral spinal cord. Neuroscience 101:393-401.

White FA, Sun J, Waters SM, Ma C, Ren D, Ripsch M, Steflik J, Cortright DN Lamotte RH, Miller RJ (2005a) Excitatory monocyte chemoattractant protein-1 signaling is up-regulated in sensory neurons after chronic compression of the dorsal root ganglion. Proc Natl Acad Sci USA 102:14092-14097.

White FA, Bhangoo SK, Miller RJ (2005b) Chemokines: integrators of pain and inflammation. Nat Rev Drug Discov 4:834-844.
Wieseler-Frank J, Maier SF, Watkins LR (2005) Central proinflammatory cytokines and pain enhancement. Neurosignals 14:166-174.

Yen CT, Honda CN, Jones EG (1991) Electrophysiological study of spinothalamic inputs to ventrolateral and adjacent thalamic nuclei of the cat. J Neurophysiol 66:1033-1047.

Yezierski RP (2001) Pain following spinal cord injury: pathophysiology and central mechanisms. In: Progress in brain research. Nervous system plasticity and chronic pain (Sandkühler J, Bromm B, Gebhart GF, eds), pp 429-449. Amsterdam: Elsevier.

Zai LJ, Wrathall JR (2005) Cell proliferation and replacement following contusive spinal cord injury. Glia 50:247-257.

Zhang J, De Koninck Y (2006) Spatial and temporal relationship between monocyte chemoattractant protein-1 expression and spinal glial activation following peripheral nerve injury. J Neurochem 97: 772-783.

Zhao P, Waxman SG, Hains BC (2007) ERK-regulated microglia-neuron signaling by PGE2 underlies pain following spinal cord injury. J Neurosci 27:2357-2368. 